\title{
ANTIFERTILITY EFFECT OF CS-1* IN THE RAT
}

\author{
YVETTE TACHÉ, J. TACHÉ AND H. SELYE \\ Institut de Médecine et de Chirurgie Expérimentales, \\ Université de Montréal, Montreal H3T 1J4, Quebec, Canada
}

(Received 5th February 1973)

\begin{abstract}
Summary. In rats, CS-1 $(5 \mathrm{mg})$ totally prevents implantation when administered by mouth during the first 8 days post coitum, but has no influence on pregnancy if treatment is initiated after the 13th day of gestation. The antifertility effect of this compound is abolished by the simultaneous injection of progesterone or prolactin. CS-1 might depress the production of pituitary luteotrophic hormone, thereby interfering with the secretory function of the corpus luteum and diminishing the supply of progesterone below the level required to maintain pregnancy.
\end{abstract}

\section{INTRODUCTION}

Recently, certain catatoxic steroids were shown to increase the metabolic degradation of many steroid hormones, including progesterone (Selye, 1971; Zsigmond \& Solymoss, 1971; Einarsson \& Gustafsson, 1973). Studies on the antifertility effect of some steroids, chosen on the basis of their catatoxic properties, have not demonstrated a relationship between these two activities (Selye, Taché \& Szabo, 1971). However, CS-1 (an anti-mineralocorticoid and catatoxic steroid) proved to be very potent as an antifertility compound (Selye et al., 1971). The purpose of the experiments to be described here was to find out at which stage of gestation CS-1 is active, and to elucidate its possible mechanism of action by establishing whether its effect is associated with hormonal disturbances in the body.

\section{MATERIALS AND METHODS}

In all our experiments, we used primiparous Holtzman/Sprague-Dawley rats (Madison, Wisconsin, U.S.A.) with a mean initial body weight of $250 \mathrm{~g}$ (200 to $300 \mathrm{~g}$ ). Each animal was kept in a separate cage and allowed free access to Purina Laboratory Chow (Ralston Purina Co. of Canada) and tap water. Insemination was determined by the identification of spermatozoa in the vagina (Day 1 of pregnancy).

In the first experiment (designed to find out at which stage of gestation CS-1 was most likely to interfere with pregnancy), ninety rats were allocated to ten

* For Catatoxic Steroid No. 1 or $9 \alpha$-fluoro-11 $\beta, 17$-dihydroxy-3-oxo-4-androstene-17 $\alpha$ propionic acid potassium salt (Searle). Manufacturer's code number: SG-11927. 
groups (Table 1). Cholesterol, a control substance having neither hormonal nor catatoxic properties, or CS-1 was administered throughout pregnancy, or for 5 days at various stages. Both compounds were given at the dose of $10 \mathrm{mg} /$ $100 \mathrm{~g}$ body weight, twice daily by stomach tube, in 1-ml aqueous suspensions homogenized with a few drops of Tween 80 . Pregnancy was verified by palpation and weight gain from the 13th day. After parturition, we noted the duration of gestation, the size of the litter, and the number of implantation sites. When births failed to occur 5 days after the controls had produced viable young, the mothers were killed to determine the absence of fetuses or their partial intrauterine resorption.

In the second experiment, sixty rats were allocated to six groups (Table 2). A dose of 5 or $10 \mathrm{mg}$ CS-1/100 g body weight was given twice daily by mouth in $1 \mathrm{ml}$ water. Progesterone (Roussel) was administered subcutaneously in $0.2 \mathrm{ml}$ peanut oil at a dose of $6 \mathrm{mg} / \mathrm{rat} /$ day. Prolactin (Ferring AG) was injected subcutaneously twice daily at a dose of $2.5 \mathrm{mg} / 100 \mathrm{~g}$ body weight in $0.4 \mathrm{ml}$ water. The presence of implantation sites was checked on the 9th day of pregnancy by direct inspection through a small laparotomy incision. At autopsy on the 21 st day, the numbers of implantation sites and fetuses in treated animals were compared with those in pregnant untreated controls. All the fetuses were then weighed. Out of these, one-third was fixed in $95 \%$ methanol, and stained with alizarin red $\mathrm{S}$ to visualize skeletal development. The other fetuses were fixed in Bouin solution and stained with haematoxylinphloxine for soft tissue examination (Wilson, 1965).

Our results were statistically evaluated by Student's $t$ test. Because the distribution may not have been normal, we also applied the Mann-Whitney (1947) non-parametric test, using White's (1952) tables of significance.

\section{RESULTS}

\section{Abortifacient action of CS-1 administered during different periods of pregnancy}

Table 1 clearly shows that CS- 1 , given orally throughout pregnancy, totally inhibited the development of term fetuses in all animals of Group 6. When treatment was limited to 5 days, antifertility activity was significant before and during nidation (Groups 7 and 8). Except for resorptions in one or two animals, autopsy generally revealed empty uterine horns without any signs of implantations.

When pregnancy continued despite CS-1 treatment, we noted some deleterious effects on the length of gestation (Groups 7 and 9) and on the number of implantation sites and fetuses (Group 7), as compared with the controls.

\section{Effect of low CS-1 doses}

According to Table 2, prevention of pregnancy was achieved more readily by low doses of CS-1 ( $5 \mathrm{mg}$ ) given on Days 3 to 10 (Group 2) than on Days 3 to 7 (Group 3). On the 9th day of gestation, no implantations were seen in either group. At autopsy, all the fetuses of Group 3 were about half the size of the controls but showed no skeletal or visceral malformations (Pl. 1, Figs 1 and 2). 


\section{PLATE 1}

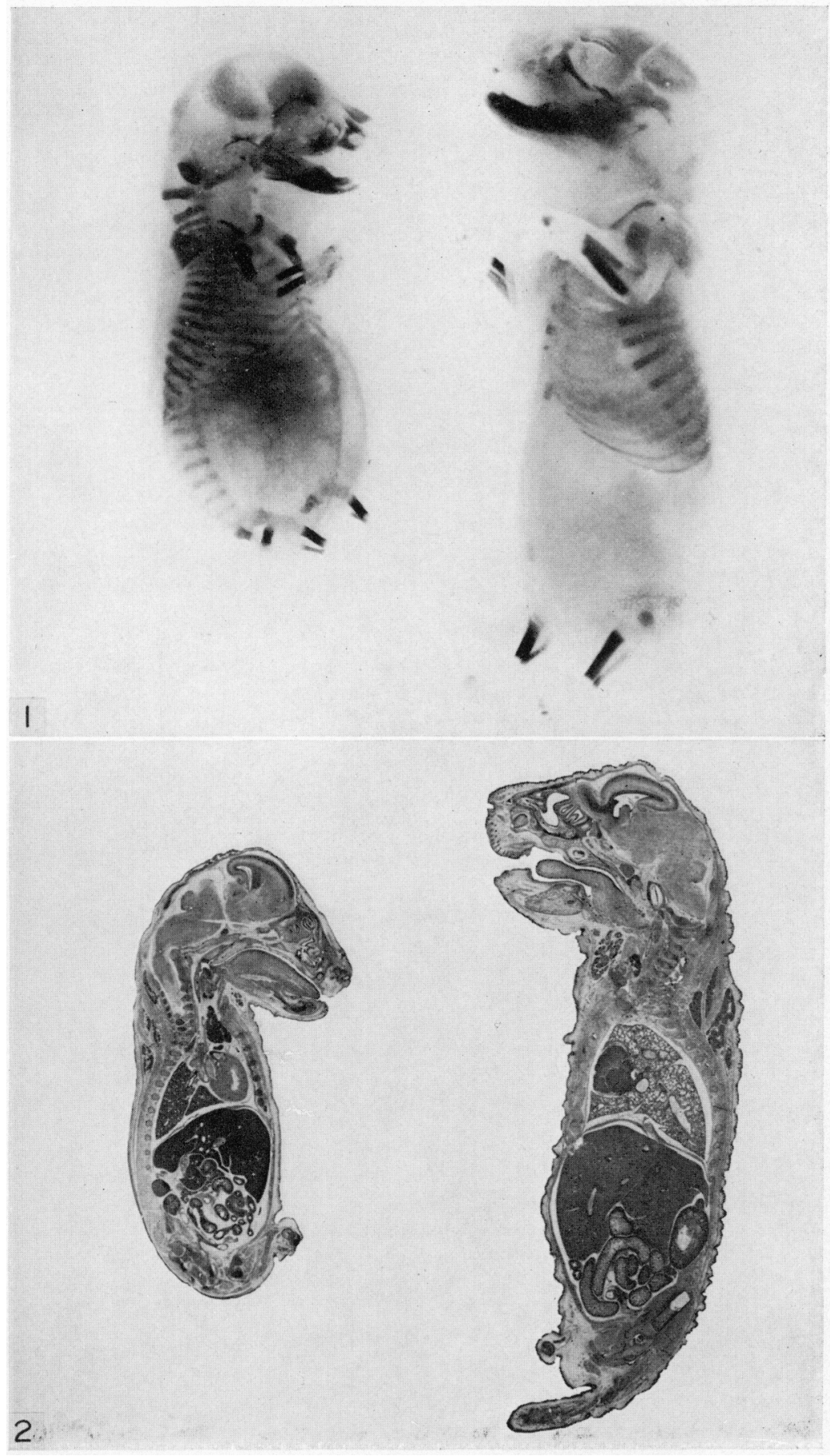

Figs 1 and 2. Fetus from CS-1-treated rat (left: Table 2, Group 3) shows no skeletal or visceral malformations but is half the size of normal fetus (right: Table 2, Group 1) on the 21 st day of gestation. Fig. 1 : methanol, alizarin red S, $\times 2 \cdot 5$. Fig. 2 : Bouin, haematoxylinphloxine, $\times 2 \cdot 5$. 


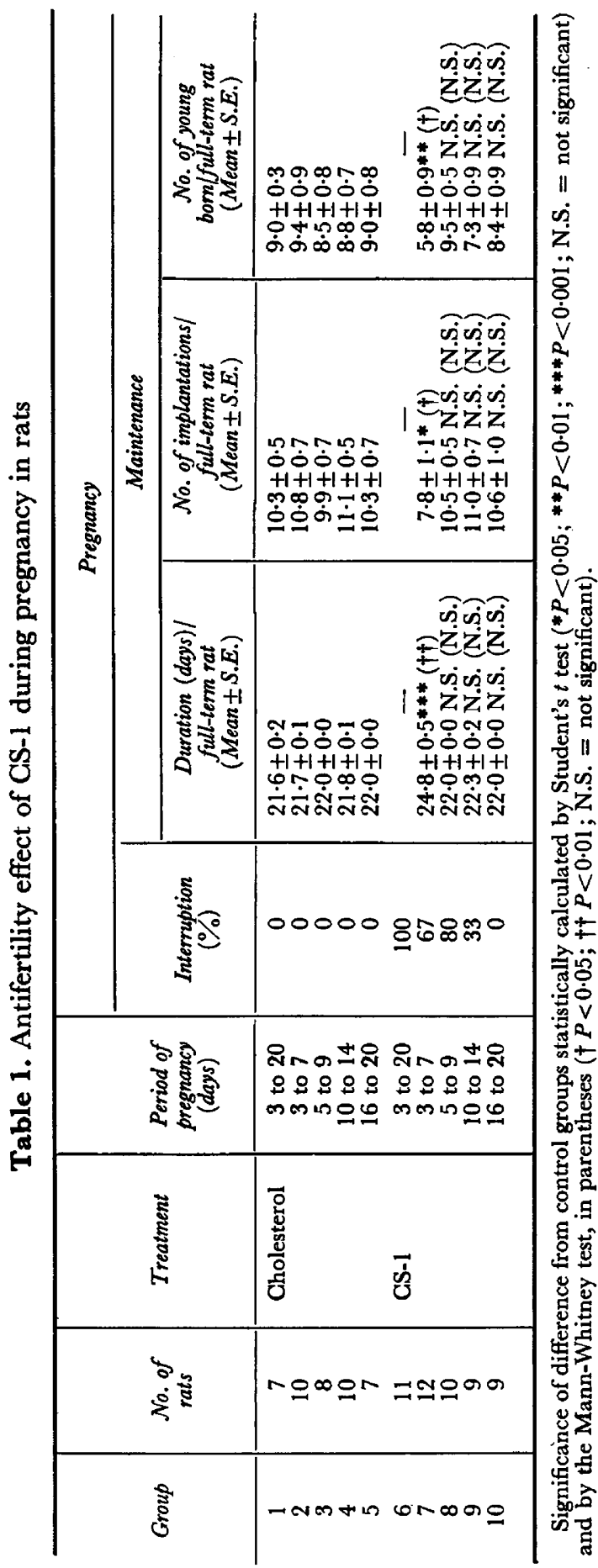


Yvette Taché et al.

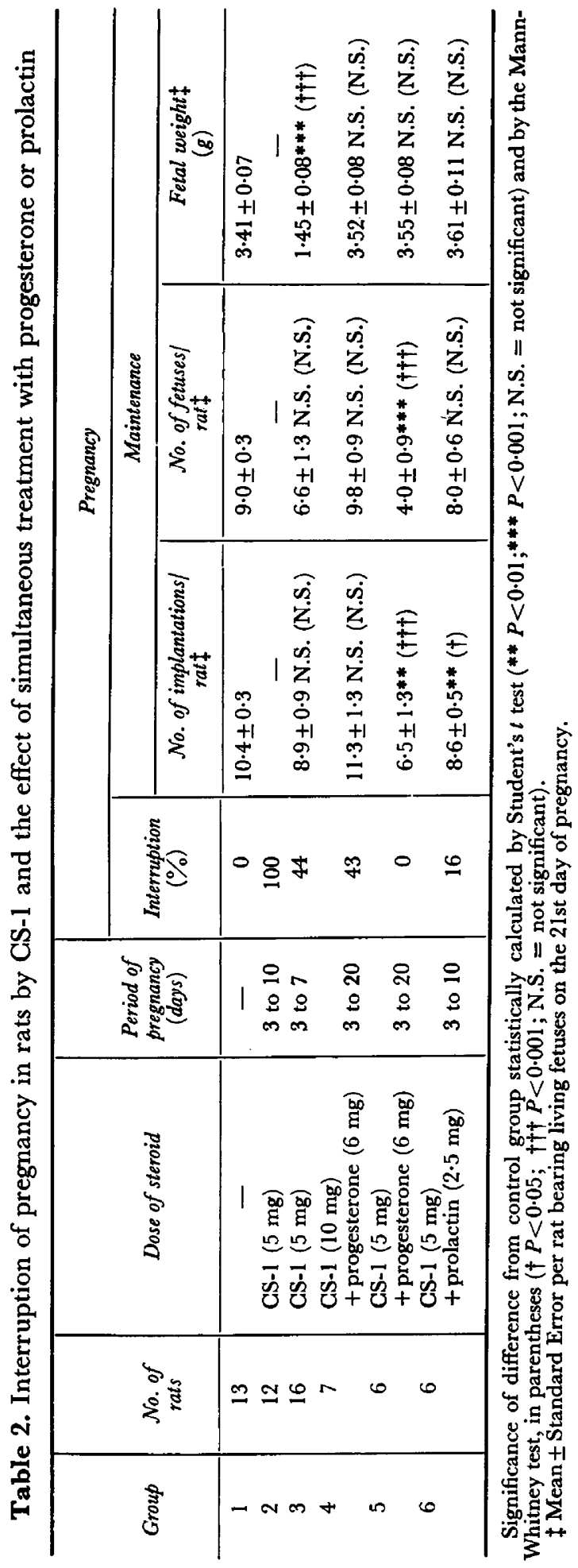


Effect of progesterone and prolactin upon the action of CS-1

Conjoint progesterone ( $6 \mathrm{mg}$ ) and CS-1 $(10 \mathrm{mg})$ treatment for 18 days caused resorption of the fetuses in three out of seven rats (Group 4); the remaining four animals carried normal litters. Progesterone and, to a lesser extent, prolactin inhibited the antifertility effect of CS-1 $(5 \mathrm{mg})$, given from the 3rd to the 10th day. However, the number of implantation sites (Groups 5 and 6) and the number of fetuses per rat (Group 5) were significantly decreased.

\section{DISCUSSION}

Even at the 5-mg dose level, CS-1, given throughout pregnancy or from the 3rd to the 10th day, appears to be $100 \%$ effective in suppressing fertility, but it has little or no interceptive activity. When pregnancy continues despite CS-1 treatment from the 3rd to the 7th day, inhibition of implantation (on the 9th day) and late parturition merely indicate delayed implantation. On the 21st day, fetuses from these rats show skeletal, visceral and weight development similar to 19-day fetuses from normal animals. Prevention of implantation by CS-1 can be reversed by progesterone and prolactin.

Chambon (1949) showed that nidation of embryos can be delayed in rats following ovariectomy on the 2 nd day.of pregnancy and treatment with $0.25 \mathrm{mg}$ progesterone per day; normal implantation can occur, however, when $0.50 \mathrm{mg}$ is given. Thus, a deficiency of progesterone could explain the absence or delay of implantation after administration of CS-1 at the beginning of pregnancy. It is also well known that a state of relative oestrogen deficiency, induced by various treatments, can cause delayed implantation (Labhsetwar, 1971). It is known that CS-1 is devoid of anti-oestrogenic properties (Drill, 1960), but the steroid may act by altering the LH content of the pituitary. Madhwa Raj \& Moudgal (1970) have shown, however, that neutralization of endogenous LH by $\mathrm{LH}$ antiserum results in interruption of pregnancy, which can be reversed by progesterone or LH but not by prolactin. In our study, prolactin greatly favoured implantation and ensured successful maintenance of pregnancy. We are therefore inclined to believe that $\mathrm{LH}$ could not have been involved in the delay or absence of implantation following administration of CS-1 at the beginning of pregnancy.

Although CS-1 is a very potent catatoxic steroid which prevents progesteroneinduced anaesthesia in vivo (Selye, 1971) by increasing hepatic microsomal drug-metabolizing enzyme activity (Werringloer, 1971), it is difficult to establish a relationship between progesterone deficiency and the biological properties of CS-1. Increased progesterone metabolism does not explain the abortifacient effect of CS-1, since known microsomal enzyme inducers such as pregnenolone$16 \alpha$-carbonitrile and phenobarbital fail to interrupt pregnancy in rats (Selye et al., 1971; Naqvi \& Warren, 1971). The antifertility activity of various steroids is related to their oestrogenicity (Harper, 1967; Jacob \& Morris, 1969). In our study, however, pregnancy was prevented by CS-1 which is devoid of oestrogenic or antiprogestational properties (Drill, 1960).

Since prolactin abolished the inhibitory action of CS-1 on implantation, the effect of the latter seems to be mediated through an hormonal disturbance 
primarily involving the luteotrophic activity of pituitary prolactin. This would also explain why CS-1 does not influence pregnancy if given after the 13th day, when the hypophysis is no longer needed for the maintenance of gestation (Selye, Collip \& Thomson, 1933). The steroid may act directly upon the pituitary or indirectly by way of the hypothalamus, or it may inactivate prolactin after the latter is released by the pituitary. Further investigations are required to locate the action site of CS-1.

\section{AGKNOWLEDGMENTS}

This work was supported in part by the Medical Research Council of Canada (Block Term Grant MT-1829), Succession J. A. DeSève and the Colonial Research Institute, Freeport, Bahamas.

The authors wish to thank the following companies for the compounds used in these experiments: G. D. Searle \& Co. (GS-1), Roussel (Canada) Ltd (progesterone) and Ferring AG (prolactin).

\section{REFERENGES}

Ghambon, Y. (1949) Réalisation du retard de l'implantation par les faibles doses de progestérone chez la rate. C. r. Séanc. Soc. Biol. 143, 756.

DRILL, V. A. (1960) SC-11927: an aldosterone-blocking agent. Pamphlet, Division of Biological Research, G. D. Searle \& Go., Chicago, Ill., U.S.A.

Einarsson, K. \& Gustafsson, J- $\AA$. (1973) Effects of a potent catatoxic steroid, $16 \alpha$-cyanopregnenolone, on microsomal metabolism of steroid hormones, sterols and bile acids in rats. Eur. Fnl Biochem. $32,197$.

HARPER, J. K. (1967) Effects of androstenedione on pre-implantation stages of pregnancy in rats. Endocrinology, 81, 1091.

JACOB, D. \& MorRIs, J. McL. (1969) The estrogenic activity of postcoital antifertility compounds. Fert. Steril. 20, 211.

Labhsetwar, A. P. (1971) Pituitary LH content during delayed implantation induced by different treatments in rats. Acta endocr., Copenh. 66, 122.

Madhwa RaJ, H. G. \& Moudgal, N. R. (1970) Hormonal control of gestation in the intact rat. Endocrinology, 86, 874.

ManN, H. B. \& Whitney, D. R. (1947) On a test of whether one of two random variables is stochastically larger than the other. Ann. Math. Statist. 18, 50.

NAQVI, R. H. \& WARREN, J. C. (1971) Interceptives: drugs interrupting pregnancy after implantation. Steroids, 18, 731.

SELYE, H. (1971) Hormones and Resistance. Springer, Heidelberg.

Selye, H., Collip, J. B. \& Thomson, D. L. (1933) Effect of hypophysectomy upon pregnancy and lactation. Proc. Soc. exp. Biol. Med. 30, 589.

SeLye, H., TAChÉ, Y. \& SzaBo, S. (1971) Interruption of pregnancy by various steroids. Fert. Steril. 22, 735.

Werringloer, J. (1971) Effect of phenobarbital and catatoxic steroids on hepatic microsomal mixed function oxidation reactions and cytochrome P-450. Physiologist, Wash. 14, 252.

White, C. (1952) The use of ranks in a test of significance for comparing two treatments. Biometrics, 8, 33.

Wilson, J. G. (1965) Embryological considerations in teratology. In Teratology: Principles and Techniques, p. 251. Eds. J. G. Wilson and J. Warkany. University of Chicago Press, Chicago.

Zsigmond, G. \& Solymoss, B. (1971) Influence of pregnenolone-16 $\alpha$-carbonitrile on the anesthetic effect and hepatic microsomal metabolism of progesterone in the rat. Biochem. Pharmac. 21, 541. 